\title{
Projected Performance of an InxGa1-xAs Quantum Dot Intermediate Band Solar Cell
}

\author{
Sayeda Anika Amin and Md. Tanvir Hasan
}

\begin{abstract}
Quantum Dot Intermediate Band Solar Cell (QDIBSC) is one of the emerging technologies in the solar photovoltaic arena, which has immense potential to be demonstrated as a high efficiency device. For a QDIBSC to surpass the efficiency of a single junction cell, optimization of design is required. In this work, a QDIBSC model based on In0.53Ga0.47As quantum dots has been designed and evaluated with respect to dot size and spacing. The impact of carrier lifetime on short-circuit current and open-circuit voltage is studied. The conversion efficiency has been enhanced from $27.1 \%$ to $32.62 \%$ as compared to a conventional single junction cell.
\end{abstract}

Keywords-Quantum dot; Intermediate band; InGaAs;

\section{INTRODUCTION}

Solar cell technology is one of the booming technologies in the world. In the past few years, solar energy has become a topic of great interest. One of the reasons behind is the incredible supply of solar energy. Despite being a free, inexhaustible resource, harnessing solar energy is a relatively new idea. In addition, the cost of solar photovoltaic modules has also declined with the development in the solar cell technologies [1]. However, for solar cells, to be competitive with the conventional energy sources the conversion efficiency needs to be enhanced. Currently the solar cell community is looking for ways to increase the cell efficiency, while preserving the cost. To have a cost-effective solar cell, the solar efficiency should exceed the Shockley-Queisser efficiency limit [2].

Intermediate Band Solar Cell (IBSC) is a solar cell which is designed to provide a large photo-generated current while maintaining a high output voltage[3] [4]. In a conventional GaAs single junction solar cell, only photons with energy equal to or greater than the bandgap energy Eg. is absorbed. The photons which have energy less than the bandgap energy are not absorbed and do not contribute to the overall photo-current. However, if the total bandgap is split into smaller bandgaps by introducing an additional band in between the valence and conduction band then the photons with low energies can be

\section{Sayeda Anika Amin}

MEEE Student

American International University-Bangladesh (AIUB)

Dhaka, Country

e-mail: anika.amin.30@gmail.com utilized. Also, the photons would be better matched with energy transitions between bands. The limiting efficiency of an IBSC is around $63 \%$ for a single bandgap in concentrated sunlight, which exceeds the Shockley Queisser limit [5], [6], [7].

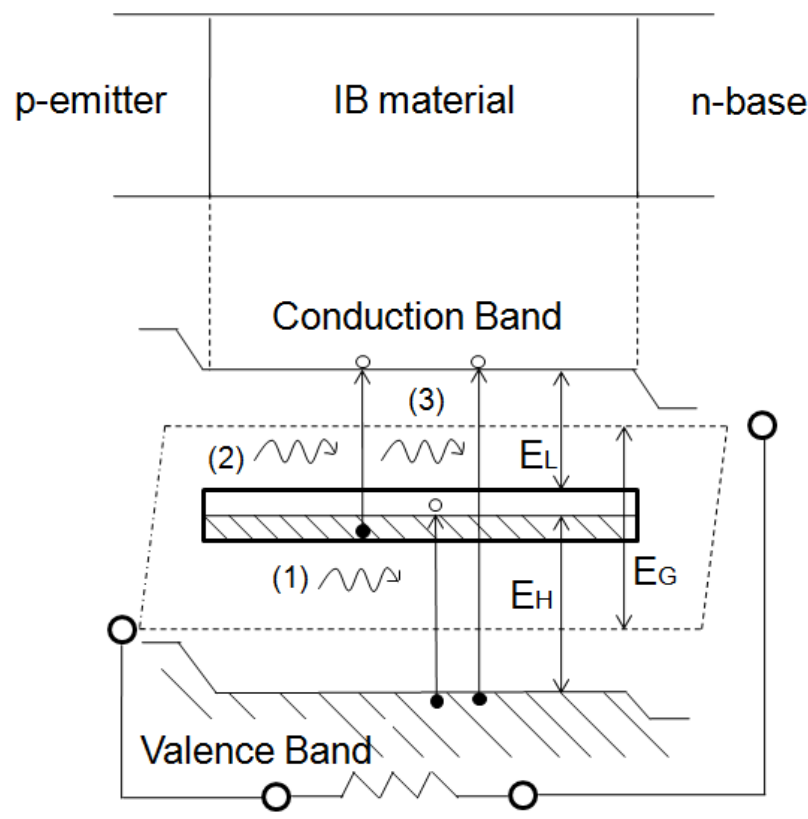

Fig. 1. Schematic diagram of an intermediate band solar cell showing the steps of photon absorption

As the intermediate band is formed between the valence band and conduction band, photons can excite the electrons from the valence band to either the intermediate or conduction band. In addition, an electrons in the intermediate band can be excited to the conduction band. So, with the conventional valence band to conduction band transition (represented by (3) in figure 1) there are two additional transitions in this device. Valence band to intermediate band transition ((1) in figure 1) and intermediate band to conduction band transition $((2)$ in figure 1). The two intermediate transitions (1) and (2) are independent of each other, while the total band gap $E_{G}$ is a sum of the two sub-bandgaps: $\mathrm{E}_{\mathrm{G}}=\mathrm{E}_{\mathrm{L}}+\mathrm{E}_{\mathrm{H}}$. Among quantum wells, quantum wires and quantum dots, only quantum dots (QDs) allow for the proper operation of the IBSC [8]. The array of quantum dots (QDs) are incorporated in the intrinsic region of a p-i-n solar cell. The intermediate band arises here from the

\section{Md. Tanvir Hasan}

Associate Professor, Dept EEE, FE

American International University-Bangladesh (AIUB)

Dhaka, Country

e-mail: mth@aiub.edu 
confined energy levels of the electrons in the conduction band [9].

Theoretical calculations suggest that quantum dot intermediate band solar cell efficiency can exceed the single junction solar cell. However, experimental efforts to fabricate quantum dot intermediate band solar cells (QDIBSC) result in a degradation of the device characteristics as compared to reference GaAs solar cells [10], [11]. In order to understand the factors, which limit the conversion efficiency such as the dot size, dot-to-dot spacing, carrier lifetime, etc. are essential to be studied. In this work, the influence of dot size, dot-to-dot spacing on the open circuit voltage as well as short circuit current of an In0.53Ga0.47As QDIBSC has been studied. In addition, the effects of carrier recombination lifetime is also investigated.

\section{THEORETICAL APPROACH}

The photocurrent of a p-i-n solar cell is evaluated by solving the minority carrier transport equation in uniform $\mathrm{p}$ type and n-type GaAs field-less regions [12]. For the incident light of wavelength $\lambda$ and flux $F(\lambda)$ the electron-hole generation rate at a depth $\mathrm{z}$, is equal to,

$$
G_{p}=(\lambda, z)=\alpha(\lambda)[1-R(\lambda)] F(\lambda) \exp [-\alpha(\lambda) z]
$$

where $R(\lambda)$ is defined as the surface reflection coefficient and $\alpha(\lambda)$ is the absorption coefficient of GaAs . Dn $(z)$, defined by the excess electron density in the p-type layer satisfies the following equation:

$$
\frac{d^{2} \Delta n(z)}{d z^{2}}-\frac{\Delta n(z)}{L_{n}}+\frac{G_{p}(\lambda, z)}{D_{n}}=0
$$

where $D n$ and $L n$ are the diffusion constant and electron diffusion length respectively. The boundary conditions represent the requirements of diminishing the excess electron density at the edge of the depletion region $\Delta n(z p)=0$ and that surface recombination absorbs the current at the front surface $(z=0)$ of the $\mathrm{p}$ layer with surface recombination velocity $\mathrm{Sn}$.

$$
\left.D_{n} \frac{d \Delta n}{d z}\right|_{z=0}=S_{n} \Delta n(0)
$$

Equation (3) can be solved analytically for the photogenerated electron current density at $z=z p$. Finally, we have,

$$
\begin{aligned}
& J_{n}(\lambda)=e F(\lambda)[1-R(\lambda)] \frac{a_{n}(\lambda)}{a_{n}(\lambda)^{2}-1} \beta_{n} \\
& {\left[b_{n}+a_{n}(\lambda)-\exp \left(-\frac{z p a_{n}(\lambda)}{L n}\right)\left[b_{n}+a_{n}(\lambda)\right]\right.} \\
& \left.\left.\cosh \left(\frac{z p}{L n}\right)+\left[1+b_{n} a_{n}(\lambda)\right] \sinh \left(\frac{z p}{L n}\right)\right]\right]
\end{aligned}
$$

where, e is the absolute value of the electronic charge, $\beta n=$ $[\cosh (z p / L n)+b n \sinh (z p / L n)-1, b n=S n L n / D n$, and $a n(\lambda)=$ $\alpha(\lambda) L n$. The total photocurrent collected by $\mathrm{p}$ type is equal to,

$$
J_{n}^{p}=\int_{0}^{\lambda_{1}} J_{n}(\lambda) d \lambda
$$

where $\lambda_{1}$ is the cut off wavelength. For the n-type region the collection of photo-current is determined similarly. As the absorption band of InGaAs dots does not overlap with the absorption band of GaAs barrier, the photo-carrier generation rate in QDs inside the intrinsic region is presented as,

$$
G D(\lambda, z)=F(\lambda)[1-R(\lambda)] \alpha_{D}(\lambda) \exp \left[-\alpha_{D}(\lambda)(z-z p)\right]
$$

where, $\alpha D(\lambda)$ is the QDs ensemble absorption coefficient. Then the photocurrent collected from the QDs is equal to

$$
J D(\lambda)=e \int_{z p}^{z p+z i} G D(\lambda, z) d z
$$

There is also some photocurrent generation in the GaAs barrier regions within the i region

$$
J_{B}(\lambda)=e \int_{z p}^{z p+z i} G B(\lambda, z) d z
$$

For the generation rate in the barrier region we consider that only the fraction $\left(1-V_{D n D}\right)$ of intrinsic region is occupied by the GaAs barrier.

$$
\begin{aligned}
& G B(\lambda, z)=F(\lambda)[1-R(\lambda)] \exp [-\alpha(\lambda) z p] \\
& \left(1-n_{D} V_{D}\right) \alpha(\lambda) \exp \left[-\left(1-n_{D} V_{D}\right) \alpha(\lambda)(z-z p)\right]
\end{aligned}
$$

Here VD is the single QD volume and $\mathrm{nD}$ is the QDs volume density. As the intrinsic region is free of traps, the built-in electric field sweeps the carrier across the depletion region and through the channels of QDs. Therefore, for the given $\lambda$, the net photocurrent generated and collected from intrinsic region is equal to

$$
J_{i}(\lambda)=J_{D}(\lambda)+J_{B}(\lambda)
$$

Total photocurrent collected from the i region is equal to

$$
J_{i}=e\left[\int_{0}^{\lambda 1} J_{B}(\lambda) d \lambda+\int_{\lambda 1}^{\lambda 2} J_{D}(\lambda) d \lambda\right]
$$

The overall photo-current must be scaled down in order to allow some recombination losses in the intrinsic region. Therefore, the short-circuit current density of the cell can be written as,

$$
J_{s c}=f_{i}\left(J_{n}^{p}+J_{p}^{n}+J_{i}\right)
$$

The conversion efficiency is calculated at the maximum power point as

$$
\eta=\frac{V_{o p t} J_{o p t}}{P_{0}}=\frac{k T}{e} \operatorname{topt}\left[J_{s c}-J_{0}\left(e^{t o p t}-1\right)\right] / P_{0}
$$

Where, $P_{0}=116 \mathrm{~mW} / \mathrm{cm}^{2}$ is the incident solar flux for one sun with AM 1.5 condition. 


\section{DeVice STRUCTURE}

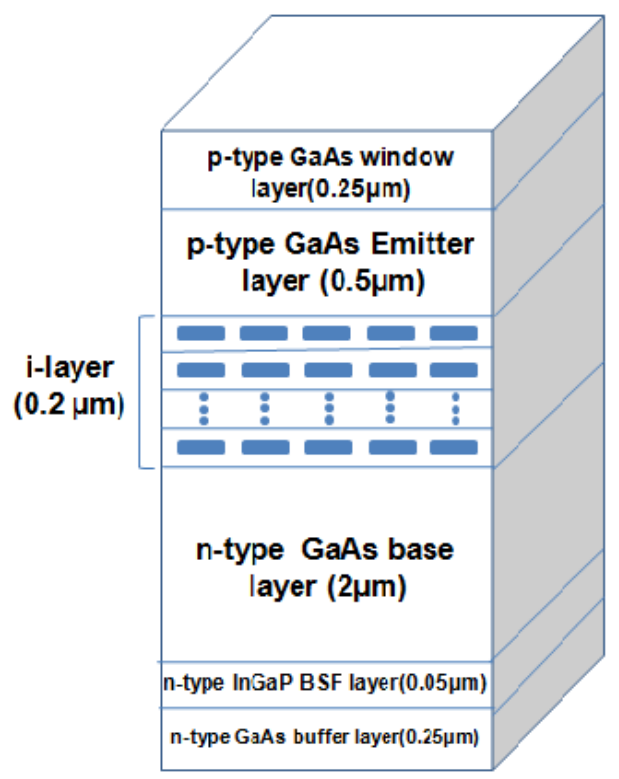

(a)

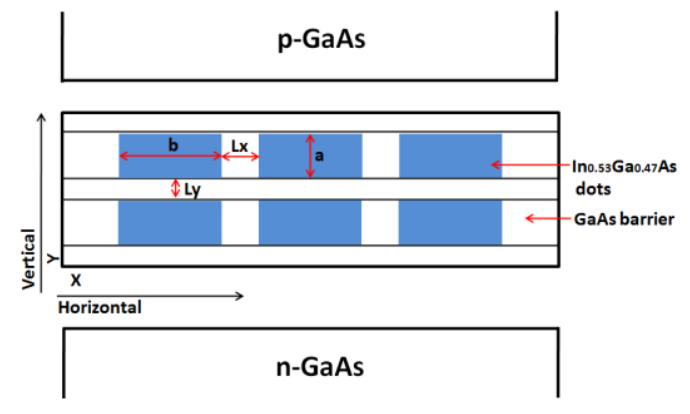

(b)

Fig. 2. (a) Schematic structure of an In0.53Ga0.47As Quantum Dot Intermediate Band Solar Cell, (b) Enlarged view of the dots in the intrinsic region.

Fig. 2(a) shows the schematic diagram of an In0.53Ga0.47As quantum dot intermediate band solar cell. The cell structure consists of a p-GaAs $(0.5 \mu \mathrm{m}), \mathrm{n}-\mathrm{GaAs}(2 \mu \mathrm{m})$. InxGa1-xAs material is employed as dots and GaAs material as barrier in the intrinsic (i) region. 15 layers of quantum dots are incorporated in the $\mathrm{i}$ region $(0.2 \mu \mathrm{m})$. The composition of Indium, $x$ used in this work is 0.53 . An $\operatorname{InGaP}(0.05 \mu \mathrm{m})$ is used as both window and back surface field layers for reducing the surface recombination at top and bottom of the solar cell.

Fig. 2(b) shows the enlarged view of the dots with dimensions. The horizontal and vertical spacing between two adjacent dots are denoted as $L_{\mathrm{X}}$ and $L_{\mathrm{Y}}$, respectively. The height of the dot is denoted as ' $a$ ' and the width as ' $b$ '. The dot size and spacing have significant effects on the device performance of a QDIBSC. These parameters are optimized for the proposed solar cell. SILVACO ATLAS software is employed to carry out the simulations. The considered physical models are low field mobility models, concentration dependent models, Shockley Read-Hall recombination models for concentration dependent lifetime, and self-consistent coupled Schrodinger Poisson model. Table 1 shows the material parameters used in the simulation.
TABLE I MATERIAL PARAMETERS USED IN SIMULATION

\begin{tabular}{|c|c|c|c|}
\hline Parameters & GaAs & InGaAs & InGaP \\
\hline Bandgap, Eg (eV) & 1.42 & 0.74 & 1.61 \\
\hline Permittivity, $\varepsilon,(\mathrm{F} / \mathrm{cm})$ & 13.2 & 14.2 & 12.1 \\
\hline Electron Affinity, $\chi(\mathrm{eV})$ & 4.07 & 4.13 & 4.4 \\
\hline $\begin{array}{l}\text { Density of states in } \\
\text { conduction band, } \mathrm{N}_{\mathrm{c}} \\
\left(\mathrm{cm}^{3}\right)\end{array}$ & $\begin{array}{l}4.35 \\
\times 10^{17}\end{array}$ & $\begin{array}{l}1.15 \\
\times 10^{17}\end{array}$ & $\begin{array}{c}7.18 \\
\times 10^{17}\end{array}$ \\
\hline $\begin{array}{l}\text { Density of states in } \\
\text { valence band, } N_{v}\left(\mathrm{~cm}^{3}\right)\end{array}$ & $\begin{array}{r}8.16 \\
\times 10^{18} \\
\end{array}$ & $\begin{array}{r}8.12 \\
\times 10^{18} \\
\end{array}$ & $\begin{array}{r}8.87 \\
\times 10^{18} \\
\end{array}$ \\
\hline $\begin{array}{l}\text { Electron Mobility, } \\
\mu_{\mathrm{n}}\left(\mathrm{cm}^{2} / \mathrm{V} . \mathrm{s}\right)\end{array}$ & 8000 & 12000 & - \\
\hline $\begin{array}{l}\text { Hole mobility, } \\
\mu_{\mathrm{p}}\left(\mathrm{cm}^{2} / \mathrm{V} . \mathrm{s}\right)\end{array}$ & 400 & 300 & - \\
\hline $\begin{array}{l}\text { Donor Concentration, } \\
\mathbf{N}_{\mathrm{D}}\left(\mathrm{cm}^{3}\right)\end{array}$ & $1 \times 10^{17}$ & - & $1 \times 10^{18}$ \\
\hline $\begin{array}{l}\text { Acceptor } \\
\text { Concentration, } \mathrm{N}_{\mathrm{A}}\left(\mathrm{cm}^{3}\right)\end{array}$ & $1 \times 10^{18}$ & - & $2 \times 10^{18}$ \\
\hline
\end{tabular}

\section{RESUlt ANALYSIS}

Based on the modeling of the quantum dot device the performance parameters such as the short circuit current density, $J_{\mathrm{SC}}$ and the open circuit voltage, $V_{\mathrm{OC}}$ are calculated. The effects of dot size and spacing on $J_{\mathrm{SC}}$ and $V_{\mathrm{OC}}$ of the device were determined.

\section{A. Dot size}

The position and width of the discrete energy level in a single dot is dependent on the size of the dot, its shape and materials used [13]. When these dots are arranged in a periodic manner forming an array of, this energy levels is turn into the intermediate band. Hence size of dots is an important factor while designing a quantum dot system. The effect of quantum dot height and width on the performance of the cell has been investigated separately. The height of the dots, is varied from 2-10 $\mathrm{nm}$. The size of dots play an important role to achieve stable, improved behavior. The sizes of dots are usually kept within $13 \mathrm{~nm}$ range [13], [14]. The effect of dot height on the current density $\mathbf{J}_{\mathrm{SC}}$ and open circuit voltage $\mathrm{V}_{\mathrm{OC}}$ is shown in fig.3. From the figure, it is seen that, the current is optimum when the height of the dot is $7 \mathrm{~nm}$, however the highest voltage is achieved at $5 \mathrm{~nm}$. Reduction of open circuit voltage is one of the main limitations of a QDIBSC system [10]. In order to preserve the voltage, the optimum height is chosen to be $5 \mathrm{~nm}$.

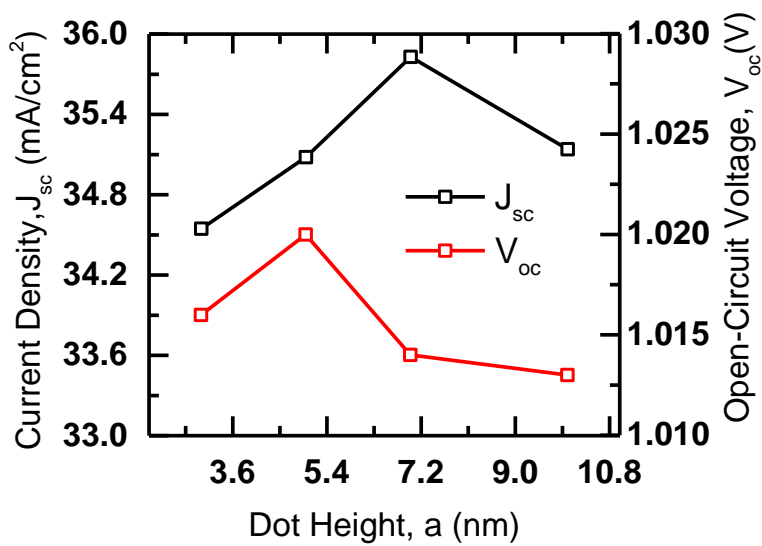

Fig. 3. Variation of current density and open circuit voltage with dot height.

Next, the width of the dot, b is varied while keeping the height constant. Fig. 4 depicts the variation of the current and voltage with the dot width. The optimum width is found to be 
$10 \mathrm{~nm}$. For $b=10 \mathrm{~nm}$, both the $\mathrm{J}_{\mathrm{SC}}$ and $\mathrm{V}_{\mathrm{OC}}$ were found to be the highest. The results suggest that, as the current and voltage are dependent on the height and width of dots, optimization of the dot size is critical for reaching high conversion efficiency in the intermediate band solar cells.

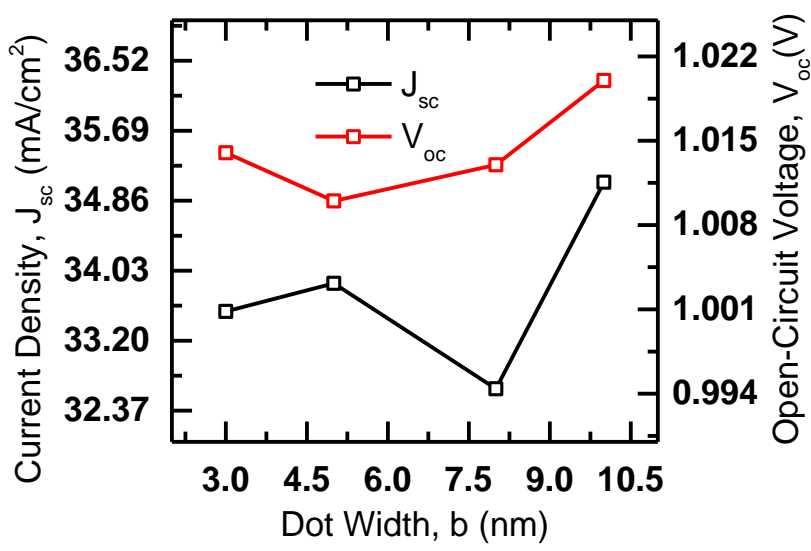

Fig. 4. Variation of current density and open- circuit voltage with dot width.

\section{B. Dot-to-dot spacing}

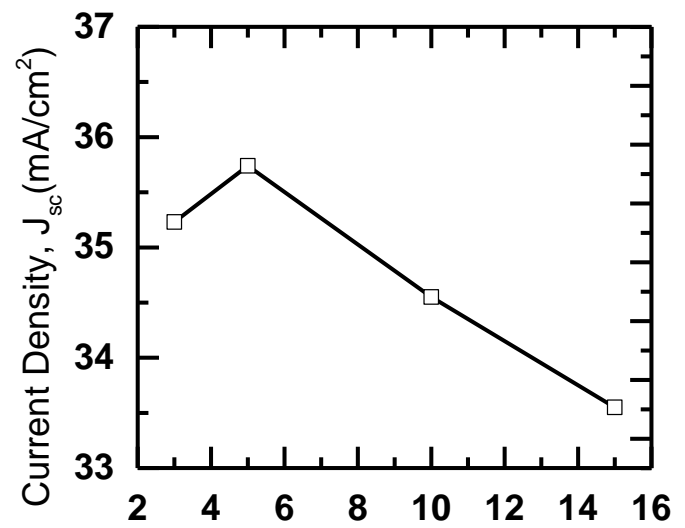

Horizontal Dot-to-Dot Spacing, $\mathrm{L}_{\mathrm{x}}(\mathrm{nm})$

Fig. 5. Effects of horizontal dot-to-dot spacing on current density.

For a QDIBSC to be efficient, the dots are required to be tightly placed in the active region [13], [15]. The horizontal and vertical dot-to-dot spacing are very crucial while designing a quantum dot system. By changing the inter-dot and vertical spacing of the quantum dot array, the device behavior and properties can be controlled to some extent. The variation of vertical spacing $\left(\mathrm{L}_{Y}\right)$ and horizontal spacing $\left(\mathrm{L}_{\mathrm{X}}\right)$ between the dots have been evaluated. The horizontal dot-to-dot spacing $\left(\mathrm{L}_{\mathrm{X}}\right)$ is varied from $3 \mathrm{~nm}$ to $15 \mathrm{~nm}$ for 15 QD layers as shown in fig. 5 , where $\mathrm{L}_{Y}=5 \mathrm{~nm}$. It is noticed that, the $\mathrm{J}_{\mathrm{SC}}$ fluctuates from $3 \mathrm{~nm}$ to $10 \mathrm{~nm}$. After $10 \mathrm{~nm}$, it starts to decrease. This decrease can be attributed to the penetration of electron wavefunction in the dot and barrier region [16], [17]. If $\mathrm{L}_{X}$ is more than $10 \mathrm{~nm}$, the electron wave-function does not penetrate the barrier region, as a result the overall current falls down. Current density is found to be optimum when $\mathrm{L}_{X}$ is $5 \mathrm{~nm}$. Fig.6 shows the effects of $\mathrm{L}_{\mathrm{X}}$ on open circuit voltage. The $\mathrm{V}_{\mathrm{OC}}$ remains almost constant with variation in $\mathrm{L}_{X}$.

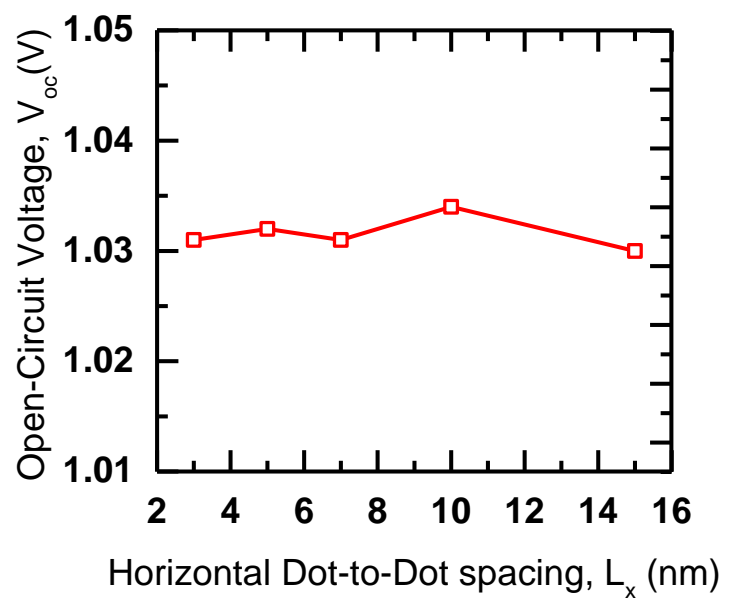

Fig. 6. Effect of horizontal dot-to-dot spacing on open-circuit voltage.

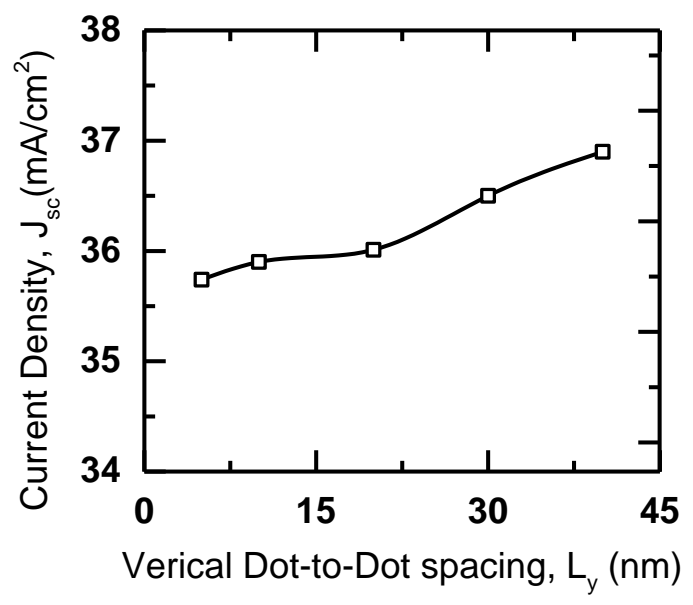

Fig. 7. Variation in current density with varying vertical dot-to-dot spacing.

After $\mathrm{L}_{X}$, vertical spacing, $\mathrm{L}_{Y}$ is varied from $5 \mathrm{~nm}$ to $40 \mathrm{~nm}$ for a fixed $\mathrm{L}_{X}=5 \mathrm{~nm}$ as shown in fig. 7 The $J_{S C}$ and $V_{O C}$ are found to be $35.04 \mathrm{~mA} / \mathrm{cm}^{2}$ and $1.03 \mathrm{~V}$, respectively for $\mathrm{L}_{\mathrm{Y}}=5$ $\mathrm{nm}$. Increasing the spacing up to $30 \mathrm{~nm}$ enhances the $\mathrm{J}_{\mathrm{SC}}$ about $1.56 \mathrm{~mA} / \mathrm{cm}^{2}$, whereas it decreases the $\mathrm{V}_{\mathrm{OC}}$ around $63 \mathrm{mV}$. A reduction in $\mathrm{V}_{\mathrm{OC}}$ is observed for further increase of $\mathrm{L}_{Y}$ above $30 \mathrm{~nm}$. The decrease in $\mathrm{V}_{\mathrm{OC}}$ is one of the main problems of QD system as it causes a drop in the overall efficiency [10],[18]. This decrease in voltage is due to the additional recombination introduced in the bandgap of dots in the i-region[10]. If the value of the $\mathrm{V}_{\mathrm{OC}}$ can be maintained up to a certain level, it leads to an increase in the device efficiency. To conserve the $\mathrm{V}_{\mathrm{OC}}$, the spacing is chosen to be $5 \mathrm{~nm}$, where the $\mathrm{V}_{\mathrm{OC}}$ is found to be the highest. The summarized results of the optimized dot size and spacing are presented in table 2.

TABLE II. SUMMARIZED RESULTS OF SIZE AND SPACING OPTIMIZATION

\begin{tabular}{|c|c|c|c|}
\hline \multicolumn{2}{|c|}{ Optimized Dot-to-dot spacing } & \multicolumn{2}{|c|}{ Optimized Size } \\
\hline Vertical & Horizontal & Height & Width \\
\hline $5 \mathrm{~nm}$ & $5 \mathrm{~nm}$ & $5 \mathrm{~nm}$ & $10 \mathrm{~nm}$ \\
\hline
\end{tabular}




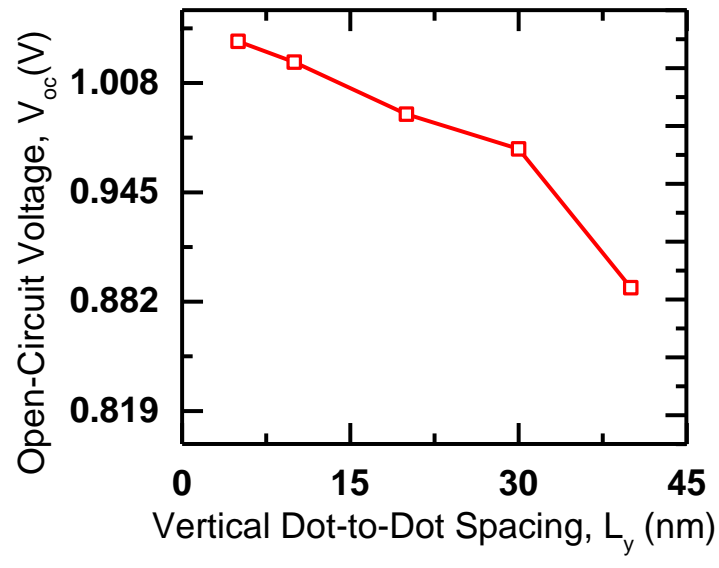

Fig. 8. Variation in open-circuit voltage with variation in vertical dot-to-dot spacing.

\section{Carrier Lifetime}

The dynamics of carriers in QDs play an important role in the overall performance of a QDIBSC. When quantum dots are placed in the intrinsic region of a QDIBSC, these dots act as recombination centers and can provide additional recombination paths for charge carriers. These recombination mechanisms can have considerable effects in the QD structures due to the capability of the quantized levels. Capture, relaxation, recombination and escape processes strongly affect the ability of a QDIBSC to exploit the absorbed extra photons [19]. The recombination lifetime strongly affect the electron density which is the underlying basis of induced photo-current in a QDIBSC. Hence determination of the recombination lifetime is very essential as it gives an indication of the induced total number of electrons reaching the collector terminals and thereby the solar photo-current and power conversion efficiency.

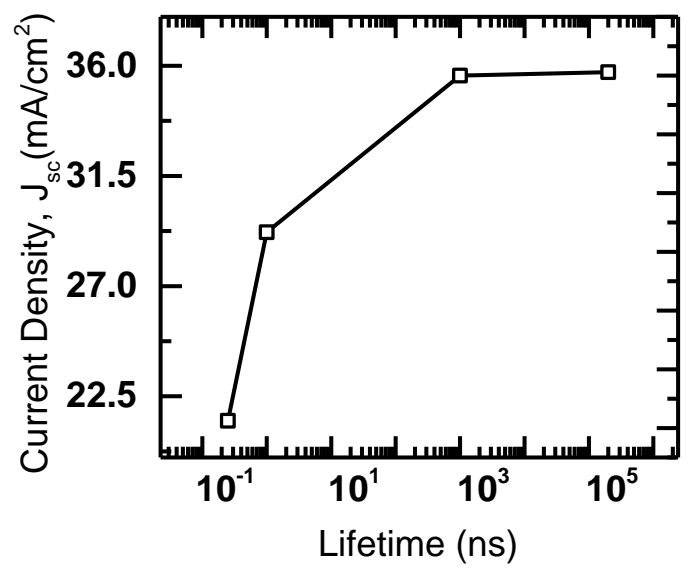

Fig. 9. Variation in current density with variation in carrier lifetime.

Figs. 9 and 10 demonstrates the effects of carrier recombination lifetime on current density and voltage. Higher lifetime implies slower carrier recombination of QDs whereas lower lifetime implies rapid carrier recombination. The recombination lifetime is varied from $20 \mu \mathrm{s}$ to $25 \mathrm{~ns}$. For rapid recombination (100 ns-25 ns), $\mathrm{J}_{\mathrm{SC}}$ and $\mathrm{V}_{\mathrm{OC}}$ are found to be significantly lower than the slower recombination $(20 \mu \mathrm{s}-100$ $\mathrm{ns})$. It is due to the fact that, for rapid recombination, the major number of charge carriers fail to arrive at the electrodes while for the slower recombination, approximately all of the charge carriers reach the electrodes, hence the generated current density increases.

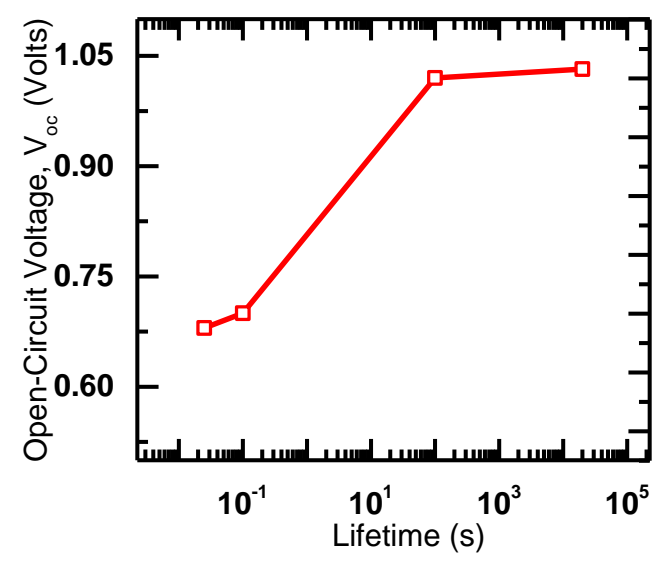

Fig. 10. Variation in open-circuit voltage with variation in carrier lifetime.

To evaluate the overall performance of the quantum dot cell, the current voltage characteristic curves are investigated. Fig 11 shows the current density, J vs. Bias voltage, V characteristic curves for the single junction solar cell and the optimized Quantum dot Intermediate Band Solar cell. The enhancement of current is found to be 30.98 to $35.74 \mathrm{~mA} / \mathrm{cm}^{2}$, which is approximately $15.4 \%$. The slight increase of voltage is also visible which is $0.03 \mathrm{~V}$. The external quantum cell while it is 0.1 in case of QDIBSC. This shows the absorption of low energy photons in the longer efficiency (EQE) of the two cells is shown in Fig. 12. From $600 \mathrm{~nm}$ to $900 \mathrm{~nm}$ an increase in the EQE is observed for the QDIBSC. This is increase is due to the thicker intrinsic region formed by the QDs. Beyond 900nm, the $\mathrm{EQE}$ is zero for single junction wavelength. Table 3 shows the summarized results of the single junction cell and the optimized QDIBSC.

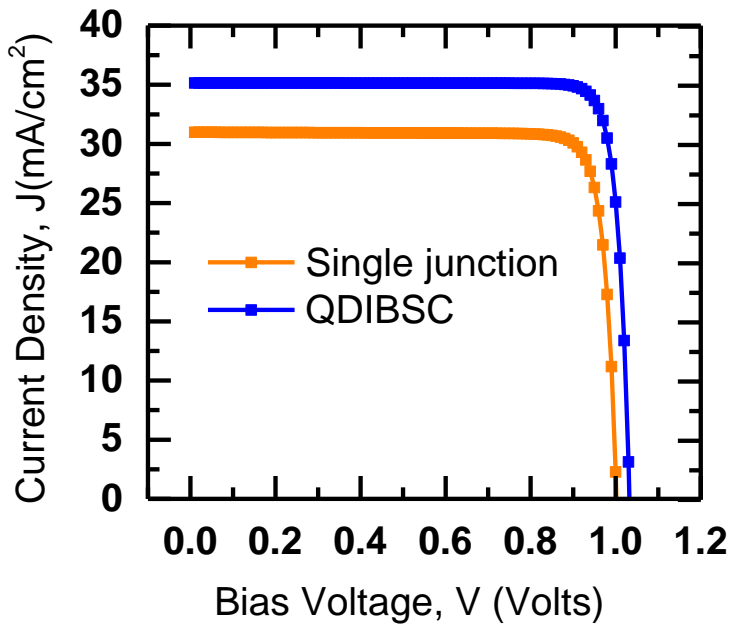

Fig. 11. J-V characteristic curves for single junction cell and optimized QDIBSC.

TABLE III. RESULTS FOR SINGLE JUNCTION AND OPTIMIZED QDIBSC DEVICES

\begin{tabular}{|l|c|c|c|}
\hline Device & $\begin{array}{c}\boldsymbol{J}_{\boldsymbol{s c}} \\
\left(\boldsymbol{m} \boldsymbol{A} / \mathbf{c m}^{2}\right)\end{array}$ & $\begin{array}{c}\boldsymbol{V}_{\boldsymbol{o c}} \\
(\boldsymbol{V})\end{array}$ & $\begin{array}{c}\boldsymbol{\eta} \\
(\boldsymbol{\%})\end{array}$ \\
\hline Single junction cell & 30.98 & 1.002 & 27.1 \\
\hline Optimized QDIBSC & 35.74 & 1.032 & 32.62 \\
\hline
\end{tabular}




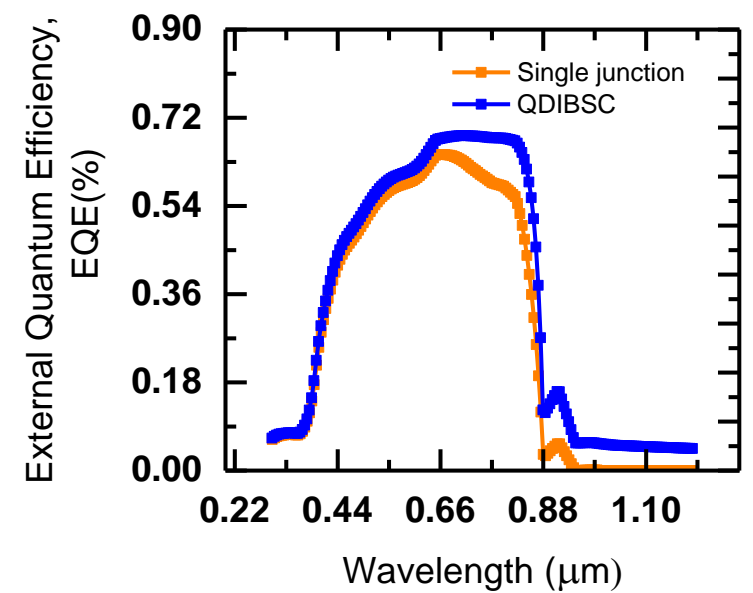

Fig. 12. External Quantum Efficiency of single junction cell and QDIBSC.

\section{CONClusion}

In this study, a model of InxGa1-xAs/GaAs quantum dot intermediate band solar cell has been presented. The size of the dots for which the efficiency is the highest is determined. The optimized height and width of the dots are found to be $5 \mathrm{~nm}$ and $10 \mathrm{~nm}$ respectively. It is found that by keeping the horizontal and vertical dot-to-dot spacing $5 \mathrm{~nm}$, the open circuit voltage of the cell can be preserved. In addition, the effect of carrier recombination lifetime on the device performance is also studied. In order to improve the performance of a QDIBSC, the dot size, spacing and lifetime need to be controlled. When comparing the results of the QDIBSC with a single junction solar cell, the conversion efficiency is found to be enhanced approximately by $20.4 \%$.

\section{REFERENCES}

[1] SolarPower Europe, "Global Market Outlook for Solar power 2015/2019", 2015.

[2] W. Shockley and H. Queisser, "Detailed BalanceLimit of Efficiency of p-n Junction Solar Cells", J.Appl.Phys., vol.32, no.3, p.510, 1961.

[3] Luque, A. \& Marti, A. Increasing the efficiency of ideal solar cells by photon induced transitions at intermediate levels. Phys. Rev. Lett. 78, 5014-5017(1997).

[4] A. Luque, P. Linares, E. Antolín, I. Ramiro, C. Farmer, E. Hernández, I. Tobías, C. Stanley and A. Martí, "Understanding the operation of quantum dot intermediate band solar cells", J. Appl. Phys., vol. 111, no. 4, p. 044502, 2012.

[5] A. Marti, L. Cuadra and A. Luque, "Quantum dot intermediate band solar cell", Conference Record of the Twenty-Eighth IEEE Photovoltaic Specialists Conference - 2000 (Cat. No.00CH37036).

[6] A. Luque, P. Linares, E. Antolín, I. Ramiro, C. Farmer, E. Hernández, I. Tobías, C. Stanley and A. Martí, "Understanding the operation of quantum dot intermediate band solar cells", J. Appl. Phys., vol. 111, no. 4, p. 044502, 2012.

[7] A. Luque and A. Mart $\tilde{\neg}$, "The Intermediate Band Solar Cell: Progress Toward the Realization of an Attractive Concept", Adv. Mater., vol. 22, no. 2, pp. 160-174, 2010.

[8] A. Luque, A. Martí and A. Nozik, "Solar Cells Based on Quantum Dots: Multiple Exciton Generation and Intermediate Bands", MRS Bull., vol. 32, no. 03, pp. 236-241, 2007.
[9] V. Aroutiounian, S. Petrosyan, A. Khachatryan and K. Touryan, "Quantum dot solar cells", J. Appl. Phys., vol. 89, no. 4, p. 2268, 2001.

[10] C. Bailey, D. Forbes, S. Polly, Z. Bittner, Y. Dai, C. Mackos, R. Raffaelle and S. Hubbard, "Open-Circuit Voltage Improvement of InAs/GaAs Quantum-Dot Solar Cells Using Reduced InAs Coverage", IEEE Journal of Photovoltaics, vol. 2, no. 3, pp. 269-275, 2012.

[11] T. Sugaya, T. Amano, M. Mori, S. Niki and M. Kondo, "Highly Stacked and High-Quality Quantum Dots Fabricated by Intermittent Deposition of InGaAs", Jpn. J. Appl. Phys., vol. 49, no. 3, p. 030211, 2010.

[12] A. Martí and A. Luque, "Fundamentals of Intermediate Band Solar Cells", Springer Series in Optical Sciences, pp. 209-228, 2012.

[13] A. Nasr and A. Aly, "Performance Evaluation of Quantum-Dot Intermediate-Band Solar Cells", Journal of Electronic Materials, vol. 45, no. 1, pp. 672-681, 2015.

[14] A. Martí, L. Cuadra and A. Luque, "Design constraints of the quantumdot intermediate band solar cell", Physica E: Low-dimensional Systems and Nanostructures, vol. 14, no. 1-2, pp. 150-157, 2002.

[15] Y. Okada, K. Yoshida, Y. Shoji, and T. Sogabe, "Recent progress on quantum dot intermediate band solar cells," IEICE Electron. Express, vol. 10, no. 17, pp. 2013200720132007, 2013.

[16] F. Benyettou, A. Aissat, M. Benamar and J. Vilcot, "Modeling and Simulation of GaSb/GaAs Quantum Dot for Solar Cell", Energy Procedia, vol. 74, pp. 139-147, 2015.

[17] S. Tomić, "Intermediate-band solar cells: Influence of band formation on dynamical processes in InAs/GaAs quantum dot arrays", Phys. Rev. B, vol. 82 , no. 19,2010 .

[18] C. Shih, M. Tan, L. Hsu, C. Tsai, C. Lin, H. Kuo, K. Chuang and T. Lay, "Numerical study of GaAs-based dual junction intermediate band solar cells", 2012 38th IEEE Photovoltaic Specialists Conference, 2012.

[19] A. Cedola, F. Cappelluti and M. Gioannini, "Dependence of quantum dot photocurrent on the carrier escape nature in InAs/GaAs quantum dot solar cells", Semiconductor Science and Technology, vol. 31, no. 2, p. 025018,2016

[20] H. Movla, H. Seifoory, S. Nikdel and S. Nikdel, "Carrier recombination effects on the performance of $\mathrm{InGaAs} / \mathrm{GaAs}$ quantum dot intermediate band solar cell: A drift-diffusion study", Optik - International Journal for Light and Electron Optics, vol. 126, no. 9-10, pp. 972-976, 2015.

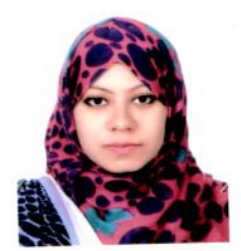

Sayeda Anika Amin received the Bachelor degrees in Electrical and Electronic Engineering from North South University in 2012. She is now pursuing Master degree in Electrical and Electronic Engineering at American International University- Bangladesh (AIUB).

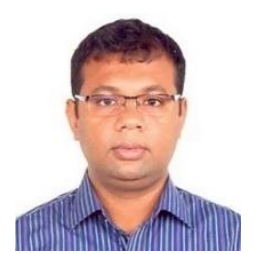

Dr. Md. Tanvir Hasan received Doctor of Engineering degree from University of Fukui, Japan in 2013. He was a Postdoctoral Research Fellow (2013-2014) in Graduate School of Engineering, University of Fukui, Japan. His research interest is focused on semiconductor devices. Currently he is working as an

Associate Professor in the department of EEE, at American International University -Bangladesh (AIUB). 